\title{
AS COMPETÊNCIAS PARA O SÉCULO XXI A PARTIR DAS METODOLOGIAS ATIVAS E O USO DAS TICS NOS PROCESSOS EDUCACIONAIS ${ }^{1}$
}

\author{
COMPETENCES FOR THE ${ }_{21}$ ST CENTURY FROM ACTIVE METHODOLOGIES AND \\ THE USE OF ICT IN EDUCATIONAL PROCESSES
}

\author{
Magda Schmidt Brasil ${ }^{2}$ \\ Maria Clotildes Felix Gabry 3
}

RESUMO: O presente artigo pretende abordar as competências para o século XXI, o uso das TICs e das metodologias ativas nos processos educacionais. A partir da web 2.0 iniciou um movimento cultural que começou a reverberar, provocando muitos impactos, nesse contexto surge a urgência de compreender melhor as transformações da sociedade moderna e principalmente os avanços tecnológicos que tornaram os processos educativos ainda mais complexos. O contexto atual nos tem levado a romper paradigmas no âmbito educacional, todos os seguimentos envolvidos nos processos educacionais precisam ressignificar papéis, a fim formar e se formar como sujeito integral compreendendo o mundo globalizado o qual estamos vivendo. Além de responder as hipóteses sobre metodologias ativas, competências e uso das TICs, vamos considerar outros fatores que permeiam os processos educacionais, como: formação continuada; e curadoria, numa abordagem mais superficial. Esse tema se originou a partir da realidade contemporânea que conjectura letramento e alfabetização digital, bem como, demanda metodologia de ensino relevante para desenvolver novas competências. Estudantes e professores precisam desenvolver as competências necessárias para esse século, e essa é uma inquietação para as instituições educacionais. No decorrer da pesquisa, vamos refletir e apontar elementos que poderão indicar de que forma competências e metodologias ativas estão conectadas e se de fato possibilitam uma dinâmica inovadora e eficaz a partir do uso das TICs.

Palavras-chave: Competências. Metodologias Ativas. TICs. Curadoria. Formação Continuada.

ABSTRACT: This article aims to address the skills for the 2ist century, the use of ICTs and active methodologies in educational processes. A cultural movement began to reverberate from the web 2.0 causing many impacts, in this context there is an urgent need to better understand the transformations of modern society and especially the technological advances that have made the educational processes even more complex. The current reality has led us to break paradigms in the educational field, all segments involved in educational processes need to reframe roles in order to form and form as an integral subject comprising the globalized world in which we are living. In addition to responding to the problem and the assumptions about active methodologies, skills and use

\footnotetext{
${ }^{\mathrm{I}}$ Este artigo apresenta alguns dos elementos estudados no Curso de Especialização em Metodologias Ativas e foi apresentado ao final do curso sob a orientação do Prof. MSc. José Aniervson Souza dos Santos.

${ }^{2}$ Mestranda em Educação- Formação de Professores Especificidade - TICs, pela FUNIBER. Graduada em Pedagogia- Supervisão Escolar pela ULBRA. Pós-graduada em Neuropsicopedagogia Clínica pela FAVENI. Pós-graduada em Metodologias Ativas pela UNINASSAU. E-mail: Magda.brasil@gmail.com

${ }^{3}$ Graduada em Pedagogia pela UNESC- RO, pós- graduação em Alfabetização pela Universidade Federal de RO.Atua na SEDUC-RO,Coordenadoria Regional de Rolim de Moura, na Coordenação dos Anos Iniciais e Finais.Coordenou PNAIC e atualmente Tempo de Aprender. E-mail: gabryclotildes@gmail.com.
} 
of ICTs, we will consider other factors that permeate educational processes such as continuing education and curation in a more superficial approach. This theme originated from the current reality that implies digital literacy and a relevant teaching methodology to develop new skills. Students and teachers need to develop the skills needed for this century, and this is a concern for educational institutions. In the course of the research, we will reflect and point out elements that may indicate how active skills and methodologies are connected and whether, in fact, they enable an innovative and effective dynamic based on the use of ICTs.

Keywords: Skills. Active Methodologies. ICTs. Curatorship. Continuing Education.

\section{INTRODUÇÃO}

O tema dessa pesquisa emergiu com a seguinte problemática: De que maneira as metodologias ativas podem contribuir para o desenvolvimento das competências a partir do uso das TICs? O problema a ser analisado no decorrer desse estudo vai elucidar qual o melhor caminho para desenvolver as competências frente aos desafios provocados pelo despontar das inovações tecnológicas, novas metodologias e ressignificação de conceitos em uma sociedade complexa.

Esse tema pode abranger todas as categorias institucionais, porém, fica mais restrito para a composição da Educação Básica e pretende responder ao problema em questão buscando uma compreensão das competências necessárias para professores e alunos, as competências da Base Nacional Comum Curricular (BNCC) pautam fatores sociais, afetivos, cognitivos e emocionais para o desenvolvimento integral do aluno que deve ser capaz de interagir no mundo moderno produzindo conhecimento. As Metodologias Ativas (MA) apresentam alguns princípios importantes que podem favorecer uma aprendizagem ativa e eficaz, mas ainda fica o grande questionamento sobre a melhor maneira de desenvolver as competências em uma sociedade de intensas transformações, principalmente no que se refere às Tecnologias da Informação e Comunicação (TIC).

A abordagem dessa pesquisa abrange competências para o século XXI no seguimento professor e no seguimento aluno contemplando uma formação holística do sujeito, que pretende refletir e analisar as metodologias e estratégias mais adequadas considerando os estímulos provocados pelas TICs sem perder de vista a diversidade no cotidiano escolar.

Compreendendo o principal objetivo dessa proposta, vamos traçar um percurso sinalizando MA como estratégias de ensino, identificar o lugar das tecnologias digitais nos processos pedagógicos e compreender o papel do aluno e do professor numa perspectiva metacognitiva (aprender a aprender). A escola do século XXI precisa inovar e enriquecer o ambiente educacional, por isso, tornou-se urgente romper o padrão educativo linear e 
pouco atrativo que desfavorece a criatividade e a diversidade em sala de aula. É nesse enfoque que abordaremos a importância das tecnologias emergentes buscando compreender se as TICs estão ou não a serviço da aprendizagem e das Metodologias Ativas para potencializar as estratégias de ensino-aprendizagem. As TICs "sacudiram" profundamente a educação e os centros escolares. Mesmo oferecendo resistência a estas mudanças, as tecnologias digitais adentraram a sala de aula sem pedir permissão (GOLDIN; KRISCAUTZKY; PERELMAN, 2015).

A Metodologia Ativa surgiu numa tendência inovadora que não comporta o conhecimento fragmentado enquanto as TICs circundam todos os setores da sociedade se tornando chave para o desenvolvimento da humanidade numa perspectiva conectivista que aborda um mundo hiperconectado e caminha para uma educação disruptiva.

Essa pesquisa tem uma sistemática bibliográfica, qualitativa e descritiva utilizando 5 palavras-chave: competências; Metodologias Ativas; TICS; curadoria; e formação continuada. $\mathrm{O}$ marco teórico se pauta em diversas literaturas clássicas e contemporâneas, revistas, caderno pedagógico, livros e artigos digitais para estudo e escolha de citações, enquanto o documento BNCC dará base legal e sustentação para toda minha produção. Além das fontes acima listadas para a construção da pesquisa também será revisitado alguns textos do Curso de Metodologias Ativas para contextualizar o conteúdo proposto durante essa Pós-Graduação e textos do material do mestrado que estou cursando pela FUNIBER (As TICs na Educação).

\section{DESENVOLVIMENTO}

\section{I Fundamentação teórica}

O tema "As competências para o Século XXI a partir das Metodologias Ativas e o uso das TICs nos Processos Educacionais"; implica conceitos pertinentes na atualidade, é possível pesquisar muitas bibliografias analisando teorias diversas de acordo com o marco teórico de cada autor.

Competência pressupõe um conjunto de habilidades, conhecimentos e atitudes que permitem colocar em prática o que foi assimilado de maneira eficaz, ao se pensar em habilidades é possível lembrar da leitura e da escrita, a competência das mesmas ocorre somente quando o sujeito aprendente é capaz de escrever, ler e interpretar o que está sendo lido, quando o estudante não desenvolve essa competência no processo de alfabetização temos uma defasagem chamada analfabetismo funcional. 
A competência surgiu com a necessidade de superar um sistema de ensino tradicional baseado na aprendizagem memorizada, a mesma fomenta conhecimentos capazes de dar respostas aos problemas reais dos alunos pensando em um planejamento curricular, que compreenda o sujeito como um sujeito holístico. Para Zabala e Arnau (2014, p. 13) competência tem significado de formação integral:

\begin{abstract}
A aprendizagem de uma competência está muito distanciada do que é uma aprendizagem mecânica; significa um maior grau de relevância e funcionalidade possível, pois para poder ser utilizada devem ter sentido tanto a própria competência quanto seus componentes procedimentais, atitudinais e conceituais (ZABALA; ARNAU, 2014, p. 13).
\end{abstract}

Descobrir como cada estudante aprende é uma atribuição docente que abrange conhecer a individualidade e subjetividade de cada sujeito aprendente, portanto, é indispensável identificar os diferentes estilos de aprendizagens antes de escolher estratégias, metodologias e ferramentas. É possível identificar diferentes modelos e estilos como defende Kolb (1976): estilo convergente, acomodador, assimilador e divergente ou ainda as múltiplas inteligências de Gardner (1998). Os tipos e estilos de aprendizagens são fatores preponderantes para garantir as competências, evidentemente o melhor caminho para adquirir competências para o século XXI é planejar estratégias, metodologias e ferramentas inovadoras para facilitar os processos educacionais.

A aprendizagem deve ser ativa em todo tempo, por isso, os métodos de questionamento que instiga a curiosidade e a experimentação frequente possibilitam conhecimentos mais profundos que resultam em competências. De acordo com Moran e Bacich (2018, p. 4I): "Metodologias ativas são estratégias que dão ênfase ao papel protagonista do aluno, ao seu desenvolvimento direto, participativo e reflexivo em todas as etapas do processo, experimentando, desenhando, criando, com a orientação do professor $[\ldots] ”$.

Parafraseando o Grupo Ser Educacional (2019), A MA foi adaptada do modelo industrial para a realidade educacional na década de $40 \mathrm{com}$ o intuito de possibilitar aprendizagem ativa colocando o estudante no centro do processo formativo. $O$ cérebro humano, suas transformações e as inteligências dependem de uma construção ativa que só é possível à medida que acontecem as interações. As interações acontecem a partir do engajamento e da colaboração entre estudantes com seus pares e estudante com seu tutor. O protagonismo na construção do conhecimento é essencial para conectar os labirintos da memória e desenvolver as inteligências enquanto a interação a partir da TIC precisa ser 
analisada a partir de uma reflexão metodológica, mais à frente veremos o conceito das Tecnologias da Aprendizagem e do Conhecimento (TACs) que complementa as TICs para práticas mais formativas e intencionalmente pedagógicas.

\subsection{Competências do professor para o século XXI}

Para uma educação democrática de qualidade é preciso pensar um educador diferente, que considera o avanço da globalização e desenvolva competências transversais, a fim de corresponder às necessidades que a sociedade moderna exige. De acordo com Funiber (2020) abordaremos 4 competências: Competência Emocional; Competência Intercultural; Competência Cidadã; e por fim e com maior destaque a Competência Digital. A Competência Emocional abrange o autoconhecimento e se refere à regulação e controle das emoções diante de inúmeros desafios. A Competência Intercultural se refere à valorização das diversas culturas e a capacidade de usar a diversidade a favor da aprendizagem. A Competência Cidadã se refere a práticas educativas contextualizadas com a ética, defesa pelos direitos e responsabilidade democrática. Por último e em maior evidência durante essa pesquisa podemos mencionar a Competência Digital que deve beneficiar as estratégias e metodologias, a fim de atingir os objetivos de aprendizagem, para desenvolver essa competência o professor precisa buscar conhecimento sobre a teoria conectivista amplamente estudada e defendida por Siemens (2004).

Diante das crescentes transformações surgem as competências emergentes exigindo um profissional resiliente e autodidata que precisa ressignificar seu ofício buscando formações de qualidade. Nesse sentido também é importante refletir sobre as io competências para o século XXI de acordo com Philippe Perrenoud.

\footnotetext{
As novas competências profissionais são constituídas por dez grandes famílias: I) organizar e dirigir situações de aprendizagem; 2) administrar a progressão das aprendizagens; 3) conceber e fazer com que os dispositivos de diferenciação evoluam; 4) envolver os alunos em suas aprendizagens e em seu trabalho; 5) trabalhar em equipe: 6) participar da administração da escola; 7) informar e envolver os pai; 8) utilizar novas tecnologias; 9) enfrentar os deveres e os dilemas éticos da profissão; ro) administrar a própria formação contínua (PERRENOUD, 2000, p. 14).
}

No contexto educacional de hoje vivemos uma espécie de transição geracional que afeta diretamente o professor e suas competências. Encontramos o grande desafio de buscar o equilíbrio entre os imigrantes digitais (professores) e os nativos digitais (alunos). $O$ professor da geração $X$ que aprendeu num formato linear, não pode transmitir conhecimento da mesma maneira para geração Y e Z. Os educadores estão numa busca 
constante para se reinventar enquanto os estudantes estão se adaptando a uma realidade na qual deixam de ser alunos para serem estudantes. A geração atual passou a receber muitos estímulos a partir da evolução da web, enquanto a geração $\mathrm{X}$ se formou numa realidade mais sólida e permanente no qual os meios de comunicação ainda eram limitados. Parafraseando Zygmund Bauman (1999) a velocidade que o conhecimento se modifica é um assunto a ser pensado e debatido, pois existe uma tendência a perder de vista o conhecimento antigo para acomodar o novo, ou seja, as novas competências podem substituir as anteriores em virtude da volatilidade de uma sociedade líquida. A teoria da aprendizagem significativa de Ausubel (1963) confirma a afirmativa de Bauman, dizendo que toda nova informação precisa de um ponto de ancoragem ou uma aprendizagem prévia para construir o conhecimento.

A partir dessa realidade, identificamos a fragilidade no âmbito pedagógico e a grande urgência em capacitar o educador a partir das novas competências, pois o mesmo não precisa mais transmitir conteúdos, já está disponível para os estudantes de diferentes formas, contudo, é fundamental mediar a aprendizagem e orientar o estudante quanto a informação ou a desinformação que chega até ele. Ensinar o estudante a selecionar o que é mais relevante facilita a construção das competências, visto que elas não podem ser ensinadas mais adquiridas, quando o estudante passa a ser o autor de seu próprio conhecimento ele assimila a aprendizagem para aplicar no cotidiano de sua vida de maneira ativa, agindo com eficiência frente a uma situação problema.

As práticas pedagógicas precisam ser mais assertivas, é necessário usar sabiamente as tecnologias digitais considerando o multiculturalismo para beneficiar os estudantes na construção das competências em um mundo globalizado e praticamente sem fronteiras que vivemos.

\subsection{Competências do aluno para o século XXI}

Por muito tempo a educação se encaminhou numa tendência conservadora e linear. Ainda hoje debatemos contra essa ideologia tradicional com origem nos aspectos históricos desde o período colonial com os colégios jesuítas e a pedagogia tecnicista que tinha como objetivo maior, formar para o mercado de trabalho. $O$ que fazer para aplicar o conhecimento adquirido na prática é a grande pergunta para o século XXI, portanto vamos analisar as ro competências para o estudante de acordo com Base Nacional Comum Curricular. 
As competências da BNCC para o século XXI abrange o desenvolvimento do estudante em todas as dimensões para intervir na sociedade. O paradigma conservador, a reprodução do ensino e a formação do sujeito passivo não se encaixa mais na realidade contemporânea, o aluno do presente e do futuro precisa desenvolver habilidades e competências emergentes assumindo uma nova performance.

Nos últimos anos já houve alguns avanços sobre a reforma de currículo e métodos pedagógicos, mas na prática ainda existe uma resistência para adaptação à nova realidade. O desafio de acompanhar as mudanças e as demandas para a atualidade pode se amparar no entendimento teórico que consolidou as competências da BNCC. De acordo com Caderno Pedagógico são elas:

\begin{abstract}
Responsabilidade e Cidadania: Agir pessoal e coletivamente com autonomia, responsabilidade, flexibilidade, resiliência e determinação. Empatia e Cooperação: Exercitar a empatia, o diálogo, a resolução de conflitos e a cooperação. Autoconhecimento e autocuidado: conhecer-se, compreender-se na diversidade humana e apreciar-se. Argumentação: Argumentar com base em fatos, dados em informações confiáveis. Trabalho e Projeto de Vida: Valorizar e apropriar-se de conhecimentos e experiências. Conhecimento: Valorizar e utilizar os conhecimentos sobre o mundo físico, social, cultural e digital. Pensamento Científico, crítico e criativo: Exercitar a curiosidade intelectual e utilizar as ciências com criticidade e criatividade. Repertório Cultural: Valorizar as diversas manifestações artísticas e culturais. Comunicações: Utilizar diferentes linguagens. Cultura Digital: Compreender, utilizar e criar tecnologias digitais de forma crítica, significativa e ética (GHIO, 2019, p. 26).
\end{abstract}

Para o século XXI não basta formar um cidadão para o mundo do trabalho, é muito mais do que isso, é formar pessoas preparadas para viver em uma sociedade democrática, formar um indivíduo competente para lutar contra a fatalidade movida por ignorância e desigualdade social. Aprender a aprender (um dos pilares da educação) também é um conceito da psicologia chamado metacognição, significa monitorar a aprendizagem e ter conhecimento do seu processo cognitivo (FLAVELL, 1976). Uma das competências que implica metacognição e têm sido muito debatidas no século XXI é a inteligência emocional estudada por Goleman (1995), a inteligência emocional é uma habilidade de administrar as emoções e controlar os impulsos, significa amadurecimento mental que potencializa a capacidade inteligível, na BNCC a identificamos como autoconhecimento e autocuidado.

Após analisar as competências, principalmente a que se refere a cultura digital é importante lembrar de uma nova geração que nasceu imersa nas tecnologias e precisa processar a alfabetização digital, não basta ser nativo digital é preciso desenvolver a competência, sendo assim, podemos inferir que Metodologias Ativas e o uso das TICs começam a dialogar convergindo para responder a hipótese inicial da pesquisa. 


\subsection{Metodologias Ativas e o uso das TICS}

No contexto educacional a MA já tem como apoio as tecnologias digitais porque pretende ir de encontro aos interesses dos alunos numa perspectiva de motivação, engajamento e aprendizagem em rede. A aprendizagem ativa é libertadora, pois possibilita autonomia e protagonismo ao estudante no processo de construção do conhecimento. Segundo Moran e Bacich (2018) a aprendizagem só é ativa quando possibilita o desenvolvimento das competências em todas as dimensões da vida, ainda de acordo com esses autores, Metodologias Ativas e modelos híbridos são conceitos poderosos para os dias atuais.

Os diferentes métodos ativos não precisam ser obrigatoriamente tecnológicos, todavia, as interfaces vêm ganhando espaço numa velocidade gigantesca ocorrendo quase uma fusão entre o mundo real e o mundo virtual, passando assim a vivenciar uma nova cultura e esse é o melhor momento para exercer a gestão do conhecimento, o que antes não era possível devido ao ensino tradicional.

São inúmeras as possibilidades quando falamos de Metodologias Ativas e elas vêm ganhando espaço ainda maior quando são associadas ao uso das TICs, porém, é fundamental compreender que o uso das TICs é indissociável da estratégia que visa alcançar os objetivos de aprendizagem. Mishra e Koehler (2006) passaram a divulgar o estudo das TICs a partir de 3 dimensões: Conhecimento Tecnológico; Conhecimento Pedagógico; e Conhecimento do Conteúdo a ser ensinado, que resulta na TPACK, que pode ser considerada mais uma competência a ser desenvolvida pelo professor, o mesmo precisa articular essas 3 dimensões em sua prática quando optar pelo uso das TICs em sua prática. $\mathrm{O}$ uso da TICs passa a ser inovação pedagógica quando contempla essas dimensões e se torna aliada de uma Metodologia Ativa com objetivos muito bem definidos e organizados, do contrário, o uso da TIC não passa de modismo.

A TIC deve estar a serviço das Metodologias Ativas, bem como da aprendizagem. Segundo o Grupo Ser Educacional (2019) existe diversas estratégias didáticas consideradas ativas como: Sala de Aula Invertida; Gamificação; Simulação, Robótica; Aprendizagem Maker; Júri Simulado; Rotação por estações; Ensino com Pesquisa; Aula Dialogada; entre outros.

Inicialmente, é importante termos em mente que a implementação de toda e qualquer mudança não é um processo fácil, principalmente ao considerarmos inovações voltadas às metodologias. $\mathrm{O}$ ato de mudar qualquer ação dentro do cenário da educação, por mais simples que seja, mostra-se uma tarefa árdua, pois 
docentes, discentes e sociedade carregam há muito tempo uma imagem de escolarização mais tradicional (RODRIGUES, 2018, p. 24).

A aprendizagem ativa se baseia em alguns princípios, são eles: aluno como protagonista; aprendizagem autônoma; prática reflexiva; resolução de problemas; atividades colaborativas; e professor como orientador, esses princípios colaboram ativamente para o desenvolvimento das competências para o século XXI (RODRIGUES, 2018).

O protagonismo se refere a participação ativa do aluno, o mesmo consegue gerir sua aprendizagem com liberdade para conduzir da maneira que ele entende ser mais produtivo, na prática reflexiva o qual o educador estimula os estudantes promovendo espaços de diálogos e troca de experiências, na resolução de problemas desenvolve-se a habilidade de aplicar a teoria na prática trazendo sentido para aprendizagem; e na atividade colaborativa onde aprende-se a fazer e conviver compartilhando saberes, quanto ao papel do professor/orientador, podemos dizer que ele passa a ser um colaborador que facilita o processo ao mesmo tempo que busca formação para qualificar sua prática pedagógica.

A caminhada de ressignificação dos papéis perpassa todos os segmentos envolvidos no contexto educacional, mais principalmente alunos e professores, os alunos passam a ser estudantes numa postura investigativa e os professores passam a ser mentores durante o processo.

\footnotetext{
Professores e alunos devem reconhecer essa relação como uma quebra de paradigma da imagem do educador como sujeito que tudo sabe e do educando como uma tábula rasa, a perceber tal desenvolvimento como a oportunidade de aprender e ensinar, de conhecer vivências diferentes e trocar experiências, tudo com o único objetivo em comum: o ato de aprender (RODRIGUES, 2018, p. 24).
}

Vamos mais além para discutir a grandeza do uso das TICs na prática do ensino híbrido que é uma mistura (blended) do ensino presencial com ensino on-line e pode tornar a aprendizagem mais interessante, as ferramentas digitais para o ensino personalizado com plataformas ou aplicativos que auxiliam na personalização do ensino onde o aluno avança enquanto o educador acompanha e orienta preenchendo lacunas em seu processo de estudo, isso é possível porque a ferramenta tecnológica fornece ao educador dados que apontam as dificuldades durante o percurso.

A diversidade que a sala de aula virtual e as plataformas de ensino possibilitam na construção cognitiva do aluno fortalecem as habilidades e competências desenvolvendo a autorregulação da aprendizagem. 
Apesar dos benefícios das tecnologias digitais para os processos educacionais apontados acima, é necessário refletir sobre algumas fragilidades, como: as distrações provocadas pelas mídias digitais que podem prejudicar o estudante; e a necessidade de inclusão digital. As distrações acabam direcionando o foco do aluno para questões de seu próprio interesse, é importante orientá-los quanto ao uso dos smartphones e redes sociais que tem sido uma fonte inesgotável de informações, quanto a inclusão digital, é indispensável uma atenção especial para inclusão através de mecanismos na esfera de políticas públicas provendo aos alunos acessibilidade a internet e recursos para que todos sejam incluídos de fato. Segundo Moran e Bacich (2014, p. 52):

\footnotetext{
As tecnologias digitais trazem inúmeros problemas, desafios, distorções e dependências que devem ser parte do projeto pedagógico de aprendizagem ativa e libertadora. No entanto, esses problemas que as tecnologias trazem não podem ocultar a outra face da moeda: é absurdo educar de costas para um mundo conectado, educar para uma vida bucólica, sustentável e progressista baseada só em tempos e encontros presenciais e atividades analógicas (que são, também, importantes).
}

O avanço da web possibilitou a criação de plataformas de aprendizagem com ambiente formativo, ferramentas de comunicação, interatividade e colaboração, podemos citar, como exemplo, as wikis, os blogs e web Quest que intensifica o compartilhamento e as produções coletivas, as redes sociais também ganham visibilidade exponencial incentivando a liberdade de expressão.

\subsection{Formação de professores e curadoria}

Por um longo período a formação de professores foi negligenciada, somente com a reforma de 1932 com Anísio Teixeira que surgiu um currículo para dar conta das exigências considerando o preparo didático pedagógico. O grande desafio para o educador hoje é sair da zona de conforto, superar as inseguranças e buscar formação, pode se distinguir a formação de professores em duas etapas, fase inicial e fase continuada, a formação inicial deve contemplar um espaço significativo para desenvolver a competência digital, enquanto a formação continuada deve aperfeiçoar ainda mais essas habilidades, principalmente quando se trata da modalidade de Ensino a Distância (EAD) que deve priorizar um maior desempenho no uso das ferramentas digitais. De acordo com Peres (2014, p. 22): "A atual sociedade digital e em rede é caracterizada pela fácil interação entre pessoas e artefatos, no sentido de construção do conhecimento e relações sociais". 
A tecnologia da informação e comunicação não pode ser reduzida unicamente a estratégias e recursos para a Educação a Distância, ela deve permear todas as modalidades educacionais.

Planejar e executar metodologias inovadoras são indispensáveis para o século XXI, bem como, desmitificar o preconceito que existe sobre a tecnologia digital em sala de aula, alguns educadores ainda não conseguem perceber a tecnologia como uma ferramenta para ser utilizada a favor da aprendizagem. A utilização das novas tecnologias é uma competência que ganhou exponencial relevância. Segundo Perrenoud (2000) as io competências para ensinar devem fazer parte do dia a dia do professor, bem como, o uso de Metodológicas Ativas que facilitem a autorregulação do estudante e a autorreflexão do docente. A prática pedagógica do educador deve estar pautada em teorias com interação e integração de novos saberes. A Teoria do Conectivismo abarca os processos de mudanças constantes devido a evolução tecnológica onde os alunos podem atribuir significado ao conhecimento, permitindo agregar valores e difundi-los com outros grupos para possibilitar a construção de conhecimentos em diferentes contextos e mídias digitais/tecnológicas. "A Teoria conectivista está relacionada com a aprendizagem como processo de mudança relativamente permanente no comportamento das pessoas" (FUNIBER, 2020, p. 19).

Da Educação Básica até o Ensino Superior é necessário pensar sobre os métodos de ensino numa perspectiva de empoderamento. Para Dimenstein e Cortella (2015, p. 69) “[...] quando falamos em educação e comunicação, falamos de empoderamento [...]”, ou seja, o indivíduo pode exercer o poder individual quando se torna protagonista, sendo assim cabe as escolas e Universidades reconfigurar os currículos com práticas e teorias interligadas, o estudante de hoje que será o educador de amanhã precisa desenvolver um perfil investigativo, vivenciar experiências ativas e significativas. O estudante/professor vai reproduzir no futuro da mesma forma que aprendeu, evidentemente o ensino superior precisa formar profissionais numa abordagem construtivista e conectivista.

Apesar da Educação a Distância ainda ter alguns aspectos a melhorar, ela potencializa a prática de todos os princípios das Metodologias Ativas, bem como facilita a formação continuada para todos com baixo custo-benefício.

As plataformas estão ficando cada vez mais interativas, favorecendo a construção colaborativa. É indispensável que cada sujeito aprendente compreenda a importância da gestão do conhecimento. Parafraseando Cortella e Dimenstein (2015): é necessário 
desenvolver a curadoria agora mais do que nunca considerando os meios de comunicação e a cultura digital o qual estamos inseridos.

A era da curadoria é um momento em que os organismos, os nossos espaços de convivência de vida comum, estruturados em algumas instituições como a escola o meio responsável por coordenar as atividades tem o espírito do curador, isso é, alguém que tem que cuidar para repartir, alguém que precisa proteger e elevar para tornar disponível, para as pessoas que ali estão, seja o conhecimento na escola, seja a informação em relação ao mundo digital (CORTELLA; DIMENSTEIN, 2015, p. I8).

Curadoria significa observar, pensar, cuidar e orientar. A obra "A era da curadoria: o que importa é saber o que Importa!"; vem justamente de encontro aos dias de hoje o qual a internet $e$ as redes sociais passaram a influenciar fortemente a maneira de ensinar $e$ aprender, curadoria é a capacidade de selecionar não somente o excesso de informações que pode prejudicar provocando distrações, mais selecionar o que realmente importa em meio a tanta diversidade, selecionar o que é mais importante para cada indivíduo em suas particularidades, selecionar amizades, trabalho, estudos, lazer entre outros:

[...] qual é o meu obstáculo a uma parcela daquilo que é o mundo digital? Ele não no dá respiro, isso é não dá trégua, o mundo não dá trégua. E sem trégua não crio, não invento. Temos um risco grande formar uma parte das gerações com a capacidade apenas de ser reiterado e não de ser criativo (CORTELLA; DIMENSTEIN, 2015, p. 77).

Não podemos dizer que a internet se tornou uma caixa de Pandora responsável por todos os males, a sociedade como um todo precisa ser educada para não se tornar refém das tecnologias e principalmente das redes sociais. É necessário administrar o tempo para desenvolver outras habilidades como criatividade e empreendedorismo. A evolução da web acabou favorecendo todas as áreas de conhecimento e principalmente o campo educacional, pois acabou transformando as políticas educacionais a partir de aplicativos, plataformas, programas tutoriais e uma infinidade de ferramentas digitais e aparatos tecnológicos.

Diante desse paradigma emergente que compreende estratégias pedagógicas eficazes para o desenvolvimento das competências é fundamental destacar que as Metodologias Ativas e as TICs são indispensáveis para favorecer a prática inovadora e a aprendizagem colaborativa.

A combinação de metodologias ativas com tecnologias digitais móveis é hoje estratégica para a inovação pedagógica. As tecnologias ampliam as possibilidades de pesquisa, autoria, comunicação e compartilhamento em rede, publicação, multiplicação de espaços e tempos; monitoram cada etapa do processo, tornam os resultados visíveis, os avanços e as dificuldades (MORAN; BACICH, 2018, p. $54)$. 
Com o advento das TICs e ferramentas digitas, as Metodologias Ativas passaram a inovar aprendizagem em sala de aula e nos ambientes informais, é possível buscar base legal para essa afirmativa a partir de consultas na Base Nacional Comum Curricular (BNCC) e na Lei de Diretrizes e Bases (LDB) que também deixa muito claro a importância das tecnologias para os processos educacionais.

\section{CONCLUSÃO}

Podemos inferir que a problemática pesquisada confirma a hipótese inicial desse artigo, mediante alguns cuidados, as Metodologias Ativas e a utilização das TICs são importantes para aquisição das competências no século XXI. É possível mensurar com mais clareza a ligação entre as Metodologias Ativas e uso das TICs em benefício da aquisição de competências com base no arcabouço teórico consultado durante a investigação.

As diretrizes da BNCC referente às competências dos alunos da Educação Básica dialogam com a implementação das Metodologias Ativas e inovadoras, é possível articular competências e estratégias adequadas de maneira eficaz desde que se valorize a formação continuada. A caminhada para aperfeiçoamento não cabe exclusivamente ao professor, os estudantes também precisam internalizar a necessidade de buscar o conhecimento com independência e autonomia buscando aperfeiçoamento durante toda a vida.

Quanto a tecnologia digital podemos afirmar que ela veio para ficar, é importante unir-se a ela por 2 motivos: primeiro porque é possível qualificar e otimizar os processos educacionais quando bem administrados; e o segundo porque o mal-uso das TICs e redes sociais podem induzir o ser humano por um caminho prejudicial. A Inteligência Artificial consegue rastrear os interesses de cada indivíduo estimulando e até manipulando através de mensagens, propagandas, feed notícias, links, fake news, entre outros, a indústria tecnológica não tem limites e a curadoria é sem dúvida uma boa estratégia para amenizar essas consequências. Cada sujeito pode exercer a curadoria e precisa ser orientado pela família e educadores.

Para finalizar essa pesquisa não poderia deixar de contextualizar as correntes teóricas que embasam de maneira explícita ou implícita esse artigo. A aprendizagem passou pelas correntes do condutismo, cognitivismo e construtivismo, no entanto, nos últimos anos passaram a se falar sobre o conectivismo que defende uma aplicação da tecnologia de forma criativa e não arbitrária. Para Siemens (2004), tanto o condutismo como o cognitivismo e o construtivismo enfocam a aprendizagem na pessoa. No entanto, 
com a tecnologia é possível que a aprendizagem ocorra também fora das pessoas, através das conexões estabelecidas com a tecnologia. Sem dúvidas as Metodologias Ativas podem se beneficiar das ferramentas digitais para desenvolver todas as competências, porém é fundamental selecionar o fluxo de informações que realmente são relevantes na construção do conhecimento.

\section{REFERÊNCIAS}

AUSUBEL, D. P. The psychology of meaningful verbal learning. New York: Grune and Stratton, 1963

BACICH, Lilian; MORAN, José. Metodologia ativas para uma educação inovadora. Porto Alegre: Penso, 2018

BAUMAN, Zygmunt. Caderno de Pesquisa. Entrevista sobre a Educação. Desafios pedagógicos e modernidade líquida. Cad. Pesqui., São Paulo, v. 39, n. 137, mai./ago. 2009. Disponível em: https://www.scielo.br/scielo.php?script=sci_arttext\&pid=SorooI574200900 0200016. Acesso em: 21set. 2020.

CORTELLA, Mario; DIMENSTEIN, Gilberto. A era da curadoria: O que importa é saber o que importa! Campinas: Papirus Editora, 2015.

Documento: "Dimensões e desenvolvimento das competências gerais da BNCC Disponível em: https://petecaportal.wordpress.com/2018/ri/o5/documento-detalhacompetencias-gerais-da-bncc-e-sua-evolucao-na-educacao-basica/ Acesso em: 2I set. 2020.

FLAVELL, J. H. Metacognitive aspects of problem solving. In: RESNICK, L. B. (org.). The nature of intelligence. Hillsdale, New York: Erlbaum, 1976. p. 231-235.

FUNIBER. As TIC na Sala de Aula. Aplicações didáticas e utilização de Recursos. Barcelona, Espanha. 2020.

FUNIBER. Os agentes formadores: o professorado/As competências para o século XXI. Barcelona. Espanha. 2020.

GOLDIN, D.; KRISCAUTZKY, M.; PERELMAN, F. Las TIC en la escuela, nuevas herramientas para viejos y nuevos problemas. Buenos Aires: Oceano Travesía, 2013.

GHIO, Mario. Caderno Pedagógico: Formação Continuada e Base Nacional Comum Curricular. №2/2019.

GOLEMAN, D. Inteligência emocional. Rio de Janeiro: Objetiva, 1995.

GRUPO SER EDUCACIONAL. Plano de ensino a partir das metodologias ativas. Recife: 2019.

KOLB, David A. The learning stylo invertoy: technical manual. Boston: Ma: McBer., 1976. 
PERES, P. Desafios e soluções para a aprendizagem digital e em rede: desafios a governação, instituições, docentes e estudantes. 2014. Ebook.

PERRENOUD.P. Dez novas competências para Ensinar. I. ed. Porto Alegre: Artemed, 2000.

RODRIGUES, Amanda. Metodologias ativas. São Paulo, 2018.

SIEMENS, G. Conectivismo: Una teoria de aprendizagem para la era digital. Vol. 15. 2014.

ZABALA, Antoni; ARNAU, Laia. Como aprender e ensinar competências. Porto Alegre: Artmed, 2014. 